\title{
Effective Assessment of Refractory Period from ECG Signal Implemented using MATLAB
}

\author{
R.Rathika, K.Sakthivel, Anitha.S
}

\begin{abstract}
The venture fundamentally concentrates on executing the present day patterns and systems in the preparing of ECG signs utilizing programming (MATLAB). The execution procedure helps us to comprehend the disadvantages and troubles of such techniques and gives us a chance to work out towards finding a superior arrangement. Such an answer would fulfill the extent of change expected in the innovations, utilized at present.For the whole stride of preparing the ECG signals we require a wellspring of the ecg.There are two approaches to accomplish it One utilizing an inbuilt matlab generator. But the wave delivered by this technique is without blunder consequently can't be utilized for handling. The other utilizing a patient's ECG from the online database as a matlab perfect document we may see that the waveform shape this technique shows mistakes and henceforth can unmistakably portray each phase of processing.Baseline meander expulsion is the following stride. It implies a meandering base. This serves as a noteworthy obstruction to data extraction. We have utilized straight separating calculation to dispense with this mistake. Control line obstruction expulsion is the following stride in handling. The electromagnetic obstructions from the powerline amid recording of ECG cause the event of 50-60Hz clamor in ECG. We have utilized wavelet change (inbuilt - wave menu) to dispose of such a blunder. The principle system of expelling every one of the mistakes is to accomplish steadfast recognition of QRS edifices. The least difficult technique for doing such method for estimation is to set up a limit esteem and recognize the buildings above it.
\end{abstract}

Keywords-ECG, standard meander, control line impedance, QRSdetection, obstinate period.

\section{INTRODUCTION}

While Electrocardiographic signs might be recorded on a longtimescale (i.e., a few days) with the end goal of recognizing discontinuously happening unsettling influences in the heart cadence. Accordingly, the created ECG recording adds up to tremendous information sizes that rapidly top off accessible storage room. Transmission of signs crosswise over open phone systems is another application in which a lot of information are included. For both circumstances, information compression is a fundamental operation and, therefore, speaks to yet another target of ECG flag preparing. It is an essential arrangement of calculations that condition the flag concerning distinctive sorts of commotion and ancient rarities, distinguish heartbeats, separate fundamental ECG estimations of wave amplitudes and spans, and pack the information for productive stockpiling or transmission; the piece graph in Fig. 1 exhibits this arrangement of flag handling calculations. In spite of the fact that these calculations are every now and again executed to work in successive request, data on the occurrence time of a pulse, as delivered by the QRS identifier, is once in a while joined into alternate calculations to improve execution. The multifaceted nature of every calculation changes from application to application. [7],[ 9], [11]

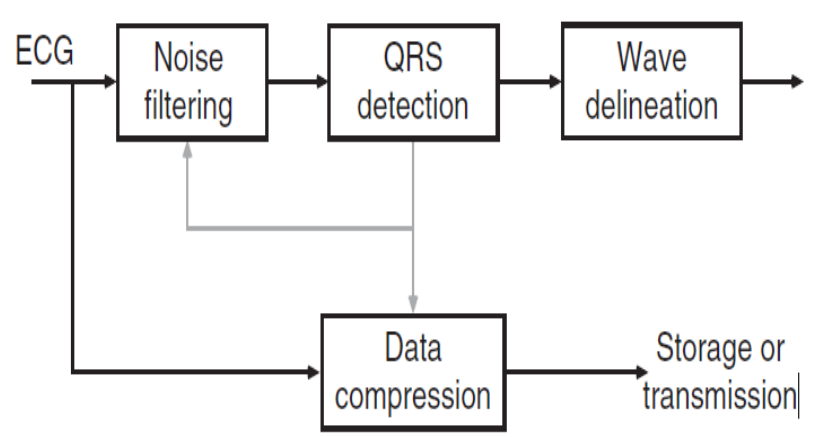

Fig. 1; The basic block diagram of ECG signal processing

\section{METHODS TO OBTAIN SOURCE OF ECG}

There are a few strategies to get the wellspring of ecg.the one which can be perfect with matlab and the one that is equipped for showing the means of handling is picked. Two such techniques are talked about beneath. [1],[3],[5]

\section{A. USE OF INBUILT MATLAB GENERATOR}

The charge that will be utilized to acquire the wellspring of ECG from matlab is:

$>$ ECG (500)

ECG (L) creates a piecewise straight ECG flag of length

The Yield Waveform Got On Execution Of Such A Guideline Is:
Revised Manuscript Received on August 22, 2019.

Rathika. R Assistant Professor ,Department of EEE,Bharath Institute of Higher Education \& Research,TamilNAdu

K.Sakthivel Assistant Professor, Department of EEE ,Bharath Institute of Higher Education \& Research,TamilNAdu

Anitha.S Assistant Professor, Department of EEE,Bharath Institute of Higher Education \& Research,TamilNAdu 


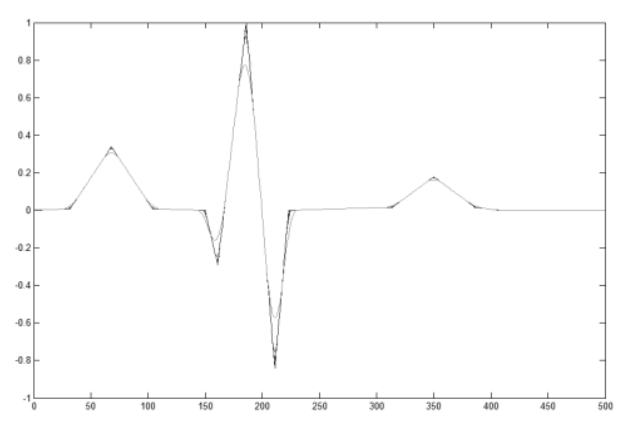

Fig. 2 waveform of ECG from matlab inbuilt generator

The flag acquired doesn't display any commotion or standard meander henceforth the handling of such a flag is undesirable

[13], [15] ,[17]

Example: Here the variable used for proceeding with further processing is "ecg ". The properties of the variable "ecg" is as follows:

\begin{tabular}{|l|l|l|l|}
\hline Name & Size & Bytes & class \\
\hline ecg & $4170 * 1$ & 33360 & $\begin{array}{l}\text { Double } \\
\text { array }\end{array}$ \\
\hline
\end{tabular}

The waveform given by these values are as follows: $>$ plot $(\mathrm{ecg})$

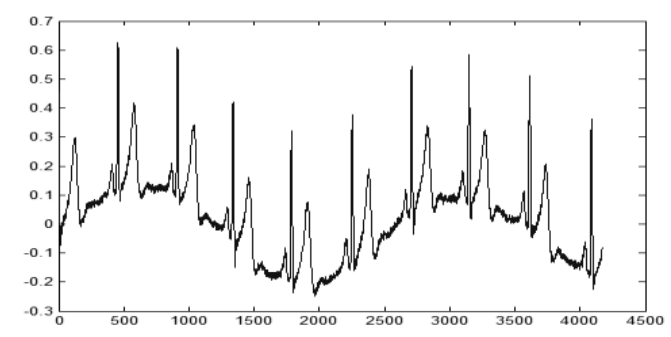

Fig. 3 waveform of ECG obtained from a database

\section{ECG PRE-PROCESSING}

Significant consideration has been paid to the plan of systems, for example, channels with the end goal of expelling pattern meander and electrical cable impedance; both sorts of aggravation infer the outline of a narrowband channel. Expulsion of clamor as a result of muscle movement speaks to another vital sifting issue being a great deal more hard to handle as a result of the generous otherworldly cover between the ECG and muscle commotion. Muscle clamor show in the ECG can; in any case, be diminished at whatever point it is suitable to utilize systems that advantage from the way that the ECG is a repetitive flag. For instance, gathering averaging strategies can be effectively connected to time-adjusted heartbeats for decrease of muscle commotion. The separating strategies are fundamentally utilized for pre-handling of the flag and have in that capacity been implementedin a wide assortment of frameworks for ECG investigation. It ought to be recalled that separating of the ECG is relevant and ought to be performed just when the sought data stays undistorted. This vital understanding might be ex $\neg$ emplified by separating for the expulsion of electrical cable inter $\neg$ ference. Such separating is appropriate in a framework for the investigation of heart rate fluctuation, though it is improper in a framework for the examination of smaller scale possibilities; as such potentials frightfully cover the electrical cable obstruction. [19],[21]

A.Baseline wander

Expulsion of gauge meander is required with a specific end goal to minimize changes in beat morphology that don't have cardiacorigin, which is particularly vital when inconspicuous changes in the"low-recurrence" ST portion are broke down for the diagnosis of ischemia, which might be seen, for exam $\neg$ ple, over the span of an anxiety test. The recurrence substance of benchmark meander is for the most part in the range below0.5 $\mathrm{Hz}$; be that as it may, expanded development of the body amid the last phases of an anxiety test additionally builds the recurrence substance of pattern meander. [14],[16], [18]

\section{Matlab coding to evacuate standard meander:}

$\%$ code for evacuation of standard meander $\%$

fori $=1: 1:$ length $(\mathrm{ecg})$

on the off chance that $\mathrm{i}==1$

$m(i)=e c g(i+1)-\operatorname{ecg}(i)$;

end

on the off chance that $i>1$

$\mathrm{m}(\mathrm{i})=\operatorname{ecg}(\mathrm{i})-\operatorname{ecg}(\mathrm{i}-1)$;

end

end

plot (m);

The waveform given by these values is as follows

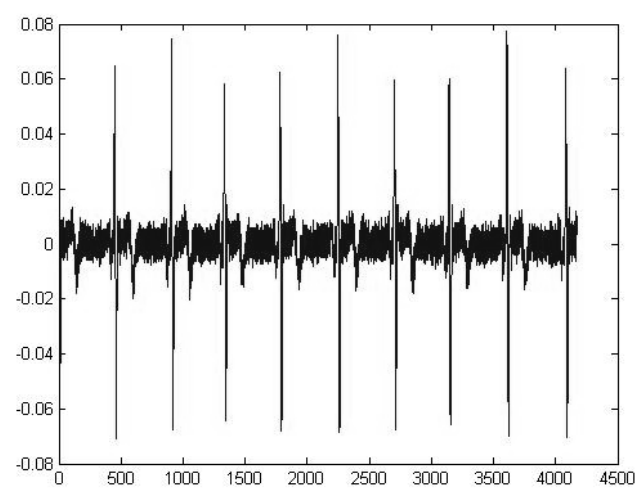

Fig. 4 waveform with baseline wander removed

\section{A. Powerline interference}

Electromagnetic fields achieved by a powerline address acommon disturbance source in the ECG that is depicted by 50 or $60 \mathrm{~Hz}$ sinusoidal check, maybe joined by different music. Such narrowband clamorren $\neg$ ders the assessment and comprehension of the ECG progressively problematic, as the delineation of low-abundancy waveforms gets the chance to be particularly faulty and deceptive waveforms may be in $\neg$ troduced. Yet extraordinary wellbeing measures can be created to reduce the aftereffects of powerline hindrance, for example, by selecting a chronicle zone with few incorporating elec $\neg$ trical devices or by appropriately ensuring and building up the zone, it may at present be imperative to perform banner taking care of to remove such impedance. A couple of techniques have been displayed therefore, going from clear immediate, band quit isolating to more adᄀvanced frameworks that handle assortments in powerline repeat 
and cover the effect of strays manifested by the occasion of QRS structures .A vital concern when filtering through powerline interference is how much the QRS buildings Influence the yield of the channel. The QRS complex acts, believe it or not, as an unfortunate, huge adequacy drive commitment to the filter. As direct, time-invariant score channels are all things considered increasingly fragile to the closeness of such inspirations, power line channels with a nonlinear structure may be ideal. In order to ensure that a channel doesn't present unacceptable distortion,its execution should be assessed by technique for replicated hails so twisting can be absolutely estimated.

\section{Matlab coding}

Procedure employing wavelet transformation:

1. Type 'wave menu' on the matlab main window

2. Now choose the 'wavelet packet 1 dimensional 'option

3 . Then load the baseline wander removed noisy variable from the workspace

4. Now perform analysis by choosing 'analyse' option

5. Similarly denoise the signal by selecting 'denoise' option

6. Now save the denoised signal for further processing

\section{Execution:}

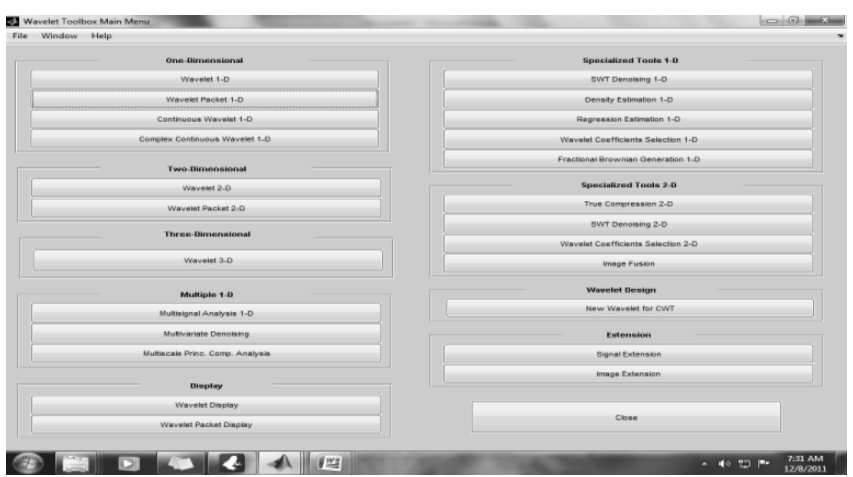

Fig.5 "wavelet toolbox main menu "window

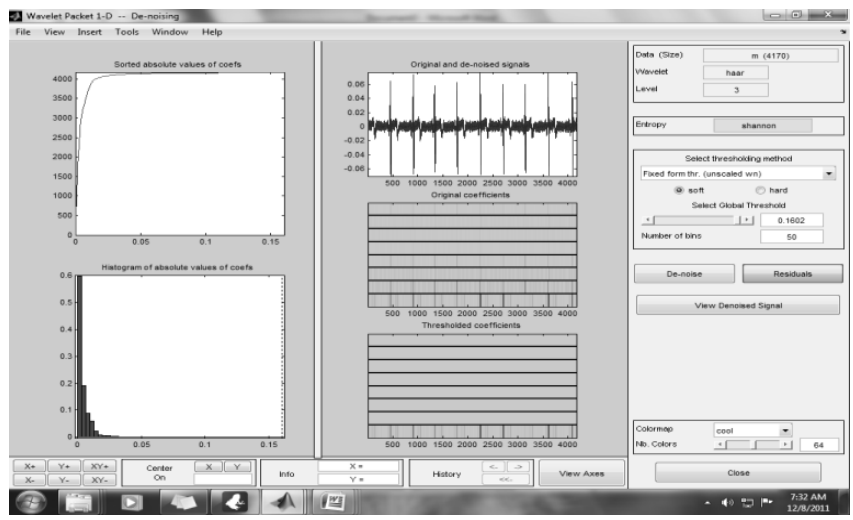

Fig. 6 "wavelet packet 1D denoising"window

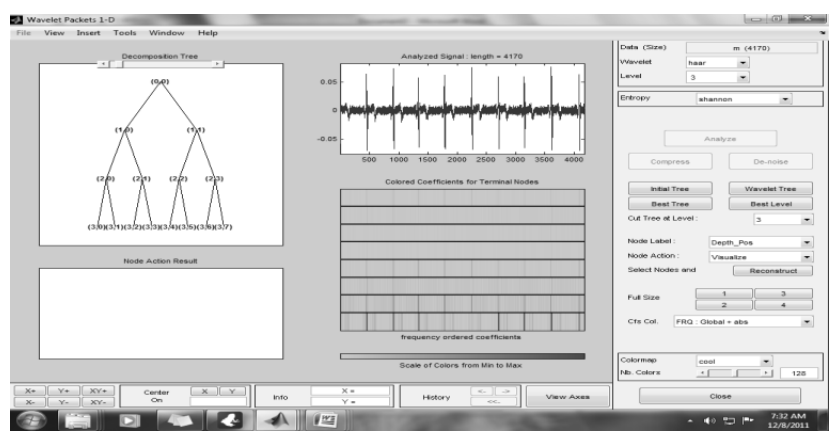

Fig. 7 "wavelet packets 1 D"window

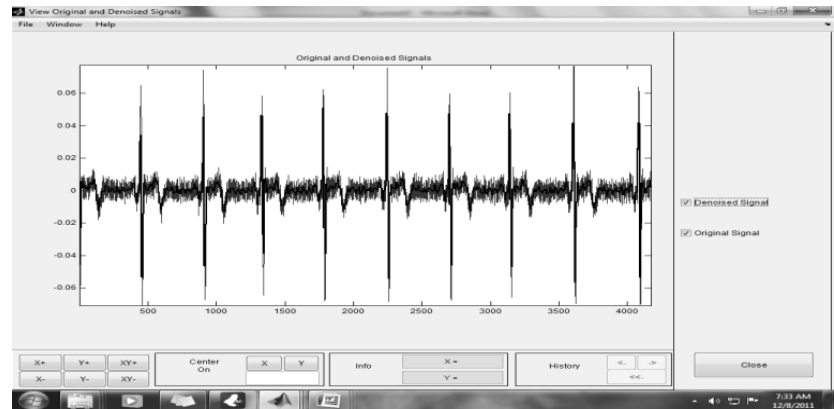

Fig. 8 "view original and denoised signal window"

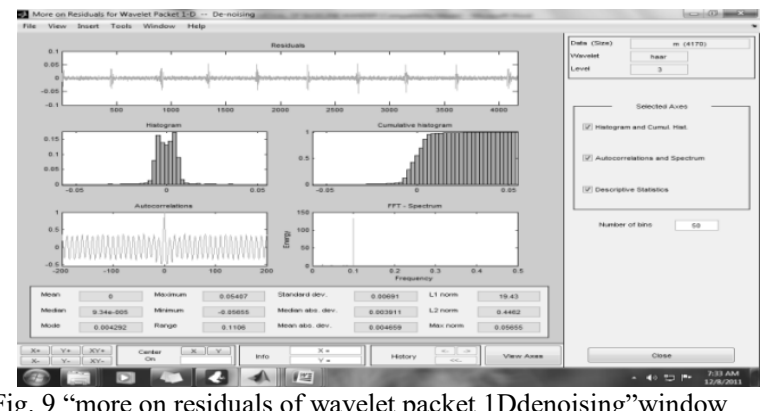

The waveform given by these values is as follows:

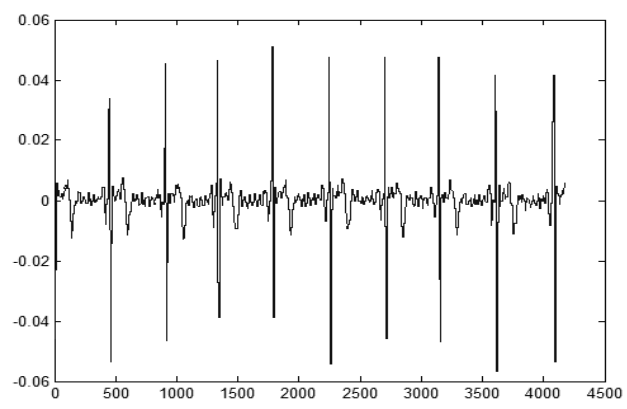

Fig. 10 waveform with powerline interference removed

\section{QRS DETECTION}

The nearness of a heartbeat and its event time is basic data required in a wide extent of ECG pennant managing. As the QRS complex is that waveform that is most effectively seen from the ECG, beat revelation is synonymous to the affirmation of QRS structures. The chart of a QRS pioneer is of fundamental significance becausepoor conspicuous evidence execution may spread subsequentprocessing steps and, thusly, restrict the general 
per $\neg$ formance of the structure. Beats that stay undetected include a more uncommon blunder than do false zone; for exam $\neg$ ple, performing blueprint of QRS morphologies. A QRS identifier must be able to perceive a noteworthy numberof diverse QRS morphologies recollecting the genuine target to be clinicallyuseful and arranged to take after startling or steady changes of theprevailing QRS morphology.. A few pioneer crucial sorts of tumult and antiquated pieces exist subordinate upon the ECG utilization of intrigue. The commotion might be fundamentally transient in nature or be of a logically unfaltering nature, asexemplified by the proximity of powerline impedance. Inthe occasion of an ECG recording with scenes containing outrageous commotion, it may be critical to ban such scenes from further examination.

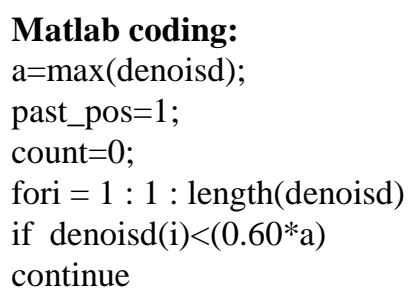

else if (i-past_pos) $>(10)$

count $=$ count +1 ;

$\operatorname{pos}(\operatorname{count})=\mathrm{i}$

$\operatorname{val}($ count $)=\operatorname{denoisd}(\mathrm{i})$;

past_pos $=\mathrm{i}$;

end

end

end

stem(pos,val);

The graph obtained after the detection of QRS complexes is as follows:

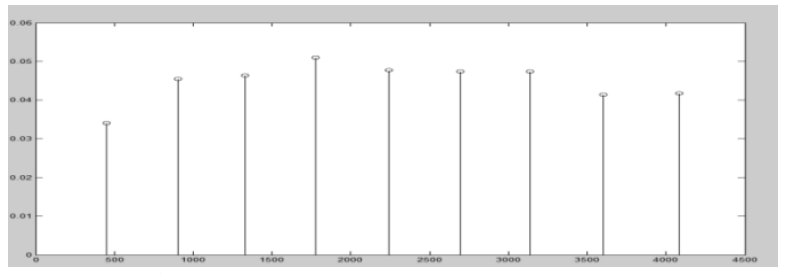

Fig. 11 waveform indicating QRS complexes

\section{REFRACTORY PERIOD ESTIMATION}

The proximity of a heartbeat and its occasion time is basic information required in a wide scope of ECG banner taking care of. As the QRS complex is that waveform that is most easily perceived from the ECG, beat disclosure is synonymous to the acknowledgment of QRS structures. The layout of a QRS discoverer is of essential centrality because poor recognizable proof execution may spread to subsequent processing steps and, in this manner, limit the general per $\neg$ formance of the structure. Beats that stay undetected establish a more extraordinary botch than do false area, while, in a perfect world, false revelations can be cleared out by, for exam $\neg$ ple, performing game plan of QRS morphologies. A QRS identifier must have the ability to distinguish a considerable number of assorted QRS morphologies remembering the true objective to be clinically useful and prepared to take after abrupt or constant changes of theprevailing QRS morphology. A couple of discoverer essential sorts of confusion and relics exist dependent upon the ECG usage of interest. The racket may be significantly transient in nature or be of a progressively persevering nature, as exemplified by the closeness of powerline impedance.

\section{Matlab coding:}

$\mathrm{x}=$ length(pos)

fori $=1: 1: \mathrm{x}$

ifi $==x$

$\operatorname{refrac}(\mathrm{x})=\operatorname{pos}(\mathrm{x})-\operatorname{pos}(\mathrm{x}-1)$;

else

$\operatorname{refrac}(i)=\operatorname{pos}(i+1)-\operatorname{pos}(i)$;

end

end

ans=mean(refrac);

disp('the average value of the refractory period estimated is '); ans

The output of such a code when executed in matlabis :

$\mathrm{x}=$

9

the average value of the refractory period estimated is ans $=456.8889$

\section{DATA COMPRESSION}

The general objective is to speak to a flag as precisely as conceivable utilizing the least number of bits, by applying either lossless pressure, in which the reconstructed signal is a correct reproduction of the first flag, or lossy compression, in which the remade flag is allowed to differ from the first flag. With lossy compression, a certain measure of contortion must be acknowledged in there constructed flag, in spite of the fact that the mutilation must remain small enough not to adjust the indicative substance of the ECG. For both sorts of pressure, it might be necessary to perform clamor separating of the ECG motion before it is subjected to information pressure.

As an extensive variety of clinical examinations include the recording of ECG signs, tremendous measures of information are delivered for quick investigation, as well as for capacity in a database for future recovery and survey. It is well-realized that the accessibility of one or a few previous ECG recordings enhances symptomatic exactness of various cardiac issue, including myocardial dead tissue. Today, such serial ECG examination includes brief length recordings gained amid rest, however may later on incorporate long flags, for instance, obtained amid stress testing or walking checking. In spite of the fact that hard disk innovation has experienced emotional changes in recent years, expanded plate size is paralleled by the steadily expanding wish of doctors to store more information. In specific, the consideration of extra ECG drives, the use of higher examining rates and better plentifulness resoluation, the incorporation of other, non cardiovascular flags, for example, circulatory strain and breath, et cetera, prompt to rapidly increasing requests on circle estimate. It is obvious that efficient strategies for information pressure will be required for quite a while to come.

An ECG banner shows a particular proportion of redun $\neg$ dancy, as appeared by connection between's neighboring models, the repeat of pulses with comparable mor $\neg$ phology, and the relative similarity between different leads. Extensive investment funds can be accomplished in wording 
of Storage limit and transmission time by misusing the different types of excess with the goal that each example can be spoken to by less bits than in the first signal. Subsequently, the information pressure calculation should represent the way that the sign contains repetitive heartbeats, oftenwith comparative morphology, and that the sign is, constantly, a multilead recording. Similarly impor $\neg$ tant, it must record for the way that both little and enormous adequacy waveforms are available in the sign, conveying significant analytic data, while the isoelectric line contains insignificant data.

Matlab coding:

$>>$ min_val $=\min (1000 *$ denoisd $)$;

>>approx_val=ceil(1000*denoisd);

>>approx_str=approx_val-min_val;

$>>$ bin_val=dec2bin((approx_str));

$>$ dec_val=bin2dec(bin_val);

>>inter_val=dec_val+min_val;

$>>$ final_res=(inter_val/1000);

$>>$ plot(final_res);

$>$ hold all;

> plot(denoisd);

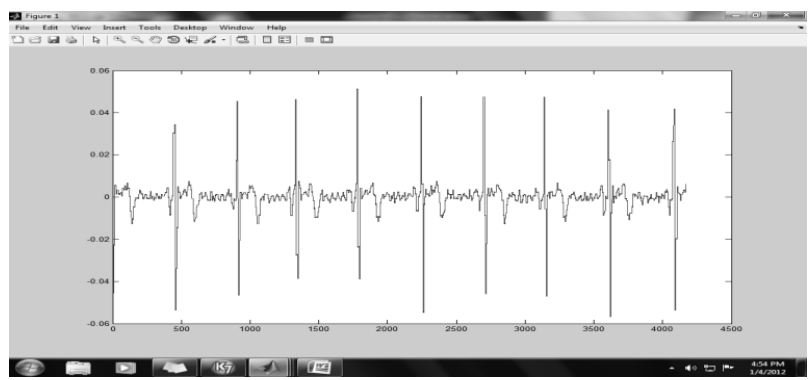

Fig. 12 waveform indicating the input and output of a data compression and expansion scheme with a scaling factor of 1000

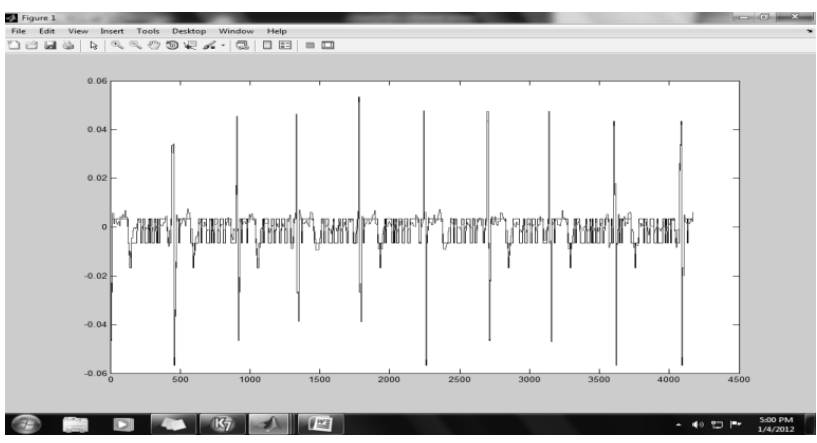

Fig. 13 waveform indicating the input and output of a data compression and expansion scheme with a scaling factor of 100

\section{PERFORMANCE EVALUATION}

The rate root mean-square distinction (PRD) is an often utilized contortion measure that evaluates the mistake between the first signal and the recon $\neg$ structed signal, characterized

$$
\mathscr{P}_{\mathrm{PRD}}=100 \cdot \sqrt{\sum_{n=0}^{N-1}(x(n)-\tilde{x}(n))^{2} / \sum_{n=0}^{N-1} x^{2}(n),}
$$

This is most commonly employed to estimate the distortion. However this method also imposes some drawbacks. That is during the evaluation of PRD for large amplitude signals, this measure always result in a low value
So we move on to a normalized parameter denoted by Prms

$$
\mathscr{P}_{\mathrm{RMS}}=\sqrt{\frac{1}{N} \sum_{n=0}^{N-1}(x(n)-\tilde{x}(n))^{2}}
$$

Matlab coding to evaluate the performance of data compression schemes used:

$\mathrm{N}=$ length(denoisd);

sum $=0$;

fori $=1: 1: \mathrm{N}$

sum=sum+((denoisd(i)-final_res(i)).^2);

end

sum_sqr= $((1 / \mathrm{N}) *($ sum $))$;

sum_sqr

rms_err=sqrt(sum_sqr);

rms_err

\section{Output:}

Case 1:

(Scaling factor used is 100)

sum_sqr =

$$
1.2655 \mathrm{e}-005
$$

rms_err =

0.0036

Case 2:

(Scaling factor used is 1000)

sum_sqr $=$

$1.0094 \mathrm{e}-007$

rms_err $=$

\subsection{1e-004}

Thus the observations reveal the presence of greater noise and error in the usage of smaller scaling factor

\section{CONCLUSION}

In this manner such a usage serves as an activity towards the advancement of a mechanized conclusion framework. Encourage there are different arrangements to change over the matlab projects to implanted c programs that tries to display an expanded execution over the equipment usage of the same. To include these methodical methodologies are obstructing their advance in the fields of present day solution like biotelemetry and so on.

\section{REFERENCES}

1. Sharma, R.K., Irusapparajan, G. \& Periyaazhagar, D. 2019, "Three-phase symmetric cascading Z-source seven levels multilevel inverter excited by multi carrier sinusoidal pulse width modulation scheme", International Journal of Innovative Technology and Exploring Engineering, vol. 8, no. 10, pp. 4269-4274.

2. Velavan, R., Bharanidharan, S. \& Sheeba, B. 2019, "EMF pollution Causes, effects and protection", International Journal of Innovative Technology and Exploring Engineering, vol. 8, no. 9 Special Issue 3, pp. 1166-1168.

3. Saravana, S., Balaji, S., Arulselvi, S. \& John Paul Praveen, A. 2019 "Reliable power quality monitoring and protection system", International Journal of Innovative Technology and Exploring Engineering, vol. 8, no. 9 Special Issue 3, pp. 644-645.

4. Tamil Selvan, S. \& Sundararajan, M. 2019, "Performance Parameters of 3 Value 8t Cntfet Based Sram Cell

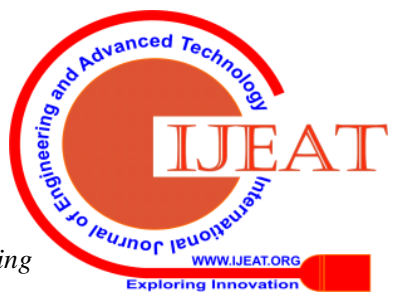


Design Using H-Spice", International Journal of Recent Technology and Engineering, vol. 8, no. 2 Special issue 5, pp. 22-27.

5. Jac Fredo, A.R., Abilash, R.S., Femi, R., Mythili, A. \& Kumar, C.S 2019, "Classification of damages in composite images using Zernike moments and support vector machines", Composites Part B: Engineering, vol. 168, pp. 77-86.

6. Kathiravan, P. \& Govindaraju, C. 2019, "Design and evaluation of ultra gain isolated DC-DC converter for photovoltaic system", International Journal of Engineering and Advanced Technology, vol. 8, no. 5, pp. 2646-2651.

7. Kripa, N., Vasuki, R. \& Kishore Kanna, R. 2019, "Realtime neural interface controlled au-pair BIMA bot", International Journal of Recent Technology and Engineering, vol. 8, no. 1, pp. 992-994.

8. Mohanraj, Meenaa Kumari, M., Philomina, S. \& Jasmin, M. 2019 "In-situ humidity measurement of hydrogen fuel cell car using MEMS sensor", International Journal of Recent Technology and Engineering, vol. 8, no. 1, pp. 41-43.

9. Velmurugan, T. \& Prakash, S. 2019, "Artificial intelligent based distribution automation of swift fault detection isolation and power restoration for HT network", International Journal of Innovative Technology and Exploring Engineering, vol. 8, no. 6, pp. 1-6.

10. Dwarakesh, K. \& Prem Kumar, G. 2019, "Five-level inverter based sequential boost system using fuzzy logic controller", International Journal of Innovative Technology and Exploring Engineering, vol. 8 , no. 6, pp. 12-19.

11. Anne Gifta, A. \& Hemavathi, G. 2019, "Analysis of grid tied solar PV system using ANFIS Algorithm", International Journal of Innovative Technology and Exploring Engineering, vol. 8, no. 6, pp. 312-316.

12. Jayavel, R., Rangaswamy, T.R. \& Prakash, S. 2019, "Efficient grid management system with renewable and conventional power sources", International Journal of Innovative Technology and Exploring Engineering, vol. 8, no. 6, pp. 287-289.

13. Hemavathi, G. \& Maheshwaran, S. 2019, "Proportional resonant controlled high gain step-up converter system with improved response", International Journal of Innovative Technology and Exploring Engineering, vol. 8, no. 6, pp. 317-323.

14. Periyaazhagar, D. \& Irusapparajan, G. 2019, "Design and completion of asymmetric single phase 27 level cascaded mli for various pwm scheme", International Journal of Innovative Technology and Exploring Engineering, vol. 8, no. 6, pp. 792-797.

15. Mahalakshmi, V. \& Vijayaragavan, S.P. 2019, "PV based powe electronic converters for high voltage DC applications", International Journal of Recent Technology and Engineering, vol. 7, no. 6, pp. 670-674

16. Irusapparajan, G., Periyaazhagar, D., Prabaharan, N. \& Rini Ann Jerin, A. 2019, "Experimental verification of trinary DC source cascaded h-bridge multilevel inverter using unipolar pulse width modulation", Automatika, vol. 60, no. 1, pp. 19-27.

17. Sangeetha, G., Sherine, S., Arputharaju, K. \& Prakash, S. 2019, "On Line Monitoring of Higher Rated Alternator using Automated Generator Capability Curve Administer", Proceedings of the IEEE International Conference on \&amp;quot;Recent Trends in Electrical, Control and Communication\&amp;quot;, RTECC 2018, pp. 176.

18. Bycil, V.J. \& Wiselin, M.C.J. 2019, "Modeling and analysis of vibration energy harvesting system using piezo stack", International Journal of Mechanical and Production Engineering Research and Development, vol. 9, no. Special Issue 1, pp. 523-533.

19. Sripada, A., Warrier, A., Kapoor, A., Gaur, H. \& Hemalatha, B. 2018 "Dynamic lateral balance of humanoid robots on unstable surfaces", International Conference on Electrical, Electronics, Communication Computer Technologies and Optimization Techniques, ICEECCOT 2017, pp. 539.

20. Srinivasan, S., Thirumalaivasan, K. \& Sivakumaran, T.S. 2018, "Performance evaluation of double-output luo converters", Journal of Advanced Research in Dynamical and Control Systems, vol. 10, no. 10 Special Issue, pp. 870-878.

21. Karthikayen, A. \& Selvakumar Raja, S. 2018, "A skellam distribution inspired trust factor-based selfish node detection technique in MANETs", Journal of Advanced Research in Dynamical and Control Systems, vol. 10, no. 13, pp. 940-949.

\section{AUTHORS PROFILE}

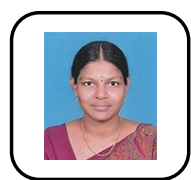

Rathika. R Assistant Professor ,Department of EEE,Bharath Institute of Higher Education \& Research,TamilNAdu

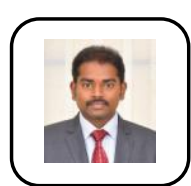

K.Sakthivel Assistant Professor, Department of EEE ,Bharath Institute of Higher Education \& Research,TamilNAdu

Anitha.S Assistant Professor, Department of EEE,Bharath Institute of Higher Education \& Research,TamilNAdu 